\title{
THE IMPACT OF GREEN INFRASTRUCTURE RAINWATER HARVESTING ON SUSTAINABLE URBANISM: CASE STUDY IN ALEXANDRIA, EGYPT
}

\author{
SALWA MOUSTAFA SHEHATA \\ Architectural Engineering Department, Menoufia University, Egypt
}

\begin{abstract}
Green infrastructure (GI) has become an urgent necessity for societies that wants to upgrade their physical fabric to respond to the needs of citizens, and to be efficiently managed and maintained. This can positively contribute to creation of liveable cities. This paper draws attention to how to integrate a rainwater management plan for GI in neighbourhoods with infrastructure problems, rainwater flooding, and considers to what extent the use of GI guides would impact the whole city. Furthermore, it demonstrates the experiences of different countries in this field and their sustainable solutions, while taking into consideration the varying scales of local factors' impacts. This paper presents a case study of the Smouha neighbourhood in Alexandria, Egypt; which was affected negatively by recent rainwater floods when there were no applications of sustainable green infrastructure.

Keywords: Alexandria, Egypt, green infrastructure, rainwater recycling, Smouha, sustainable urbanism, water management plan.
\end{abstract}

\section{INTRODUCTION}

Making liveable cities is largely determined by how efficiently their infrastructure is designed and integrated. A green infrastructure (GI) includes natural and semi-natural features that protect the natural water cycle. Rainwater management features could be present in some implementations, such as street rainwater harvesting, green roofs, green spaces and so on. When a rainwater management plan is integrated properly into the built environment, it provides social, economic and environmental benefits that enhance community liveability; therefore, it must be considered at every level of city planning, architecture and landscape strategies.

Research problem: Developing countries suffer from crumbling infrastructure problems that require more effective GI implementations; which will become the key for many future economic, social and environmental developments.

Research aim: The overarching aim of this paper is to inform officials, architects and planners about the value and benefits of GI rainwater recycling; to improve the quality of citizen's life in urban neighbourhoods in developing countries.

Research methodology: A qualitative study was implemented. This theoretical study tends to identify GI implementations and their likely impact on the environment. This is followed by a survey study and questionnaire to some residents in the Smouha neighbourhood in Alexandria, Egypt: This case study tackles rainwater problems, presents a future vision of rainwater management, and provides some proposals for planners to achieve green values that can improve the liveability in the city of Alexandria.

\section{RETHINKING THE GREEN INFRASTRUCTURE}

The GI has a vital role in cities' advancement, which cannot be underestimated. Research includes the future strategies for rainwater management working towards implementation and GI development that can be applied in urban environments, especially in developing countries, to avoid more problems occurring because of poor infrastructure; and to achieve 


\section{Social and economic services that GI could provide in urban environments:}

a common ground for sharing ; building community links;

inward investment ; a healthier population;

reducing the economic burden on health services;

\section{flood storage ; reducing pressure on city infrastructure and}

\section{Encouraging aspiration where there may be inequality.}

Figure 1: GI services and benefits.

effective GI services and benefits, as shown in Fig. 1. Furthermore, "it is crucial to recognise that urban systems do not operate in isolation they interact. This therefore suggests that for resilience to be effective, the parties involved in each urban system also need to interact and work together" [1].

\subsection{Countries' experiences and strategies in water harvesting}

In city of San Diego they have followed an alternative method to redirect rainwater, they use a rain barrel to collect and store rain water. "In Berlin rainwater utilization systems were part of a large-scale urban re-development. Rainwater falling on the rooftops of buildings is collected and stored in a rainwater basement tank, then used for toilet flushing, watering of green areas" [2].

\section{WATER HARVESTING IMPLEMENTATION}

Harvesting rainwater could be an additional feature for a sustainable home's water efficiency strategy. It could be utilized in homes for toilets, showers, and could be properly filtered for drinking; on the other hand, they could harvest to "rain" on public gardens, and for streets and parking lots' cleaning needs. It leads to a diversity of other practices that contribute to a greater sustainable environment. The research displays two implementations of rainwater management, which are street harvesting and cultivated surface harvesting. Those implementations positively affect community development, especially from the environmental side.

\subsection{Street harvesting}

\subsubsection{Street water runoff}

Street water runoff, the rainwater that falls directly on streets and pavements, then flows down gutters into the sewage. Water harvesting is the process of capturing and storing the rainwater from streets, then reusing it for irrigation, car washing and other potential uses. This process treats rainwater as a resource and implements green gutters, rainwater planters, rainwater bump out and rainwater tree trenches, as shown in Fig. 2. 


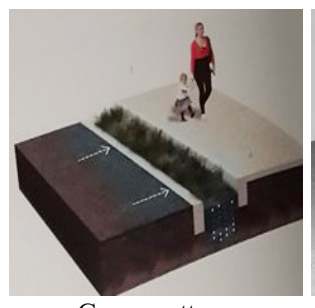

Green gutter

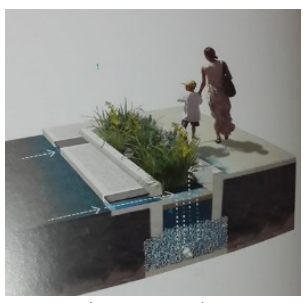

Rain water planter

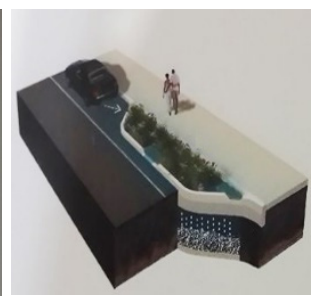

Rain water bump out

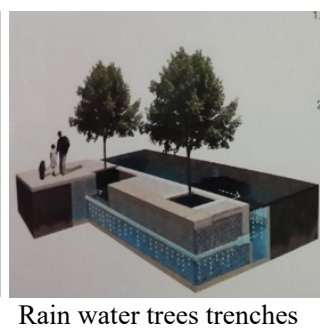

Figure 2: Street water harvesting features [3].

\subsubsection{Permeable pavements}

There are different types of permeable pavement that allow water to pass through the surface, percolate through the existing subsoil and provide rainwater storage, as shown in Fig. 3.

\subsection{Cultivated surface harvesting}

The term "cultivated surfaces" refers to any planted area, both on building rooftops called a "green roof" or in public green spaces, such as planted gardens.

\subsubsection{Green roof}

A green roof is a rooftop covered with cultivated vegetation (plants); it involves high-quality waterproofing and drainage systems. It also includes a root barrier, drainage and irrigation systems. Harvested rainwater can be used to irrigate these rooftop crops.

There is enormous potential for harvesting roof rainwater, as it can directly irrigate plants on green roofs or transfer by gutters to rain barrels or a basement tank, then be collected and stored for other landscaping and cleaning use. A "huge range of large single storage tanks can be manufactured from plastic, metal or fibreglass, and range in size from 50 gallons to thousands of gallons," as shown in Fig. 4 [4].

\subsubsection{Green spaces and public gardens}

Green spaces and gardens have a multitude of benefits and provide many services that have ecological, economic and social implications. Rainwater harvested from streets and barrels can be utilized and managed to irrigate these planted spaces.

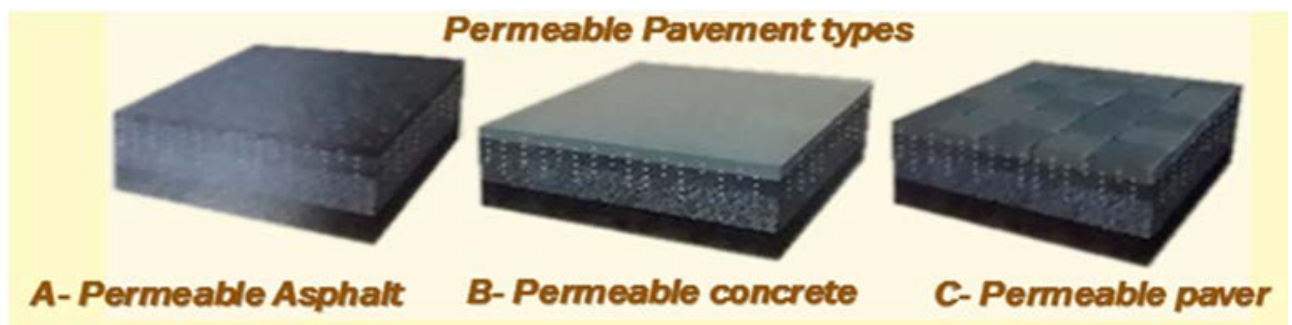

Figure 3: Types of permeable pavements [3]. 


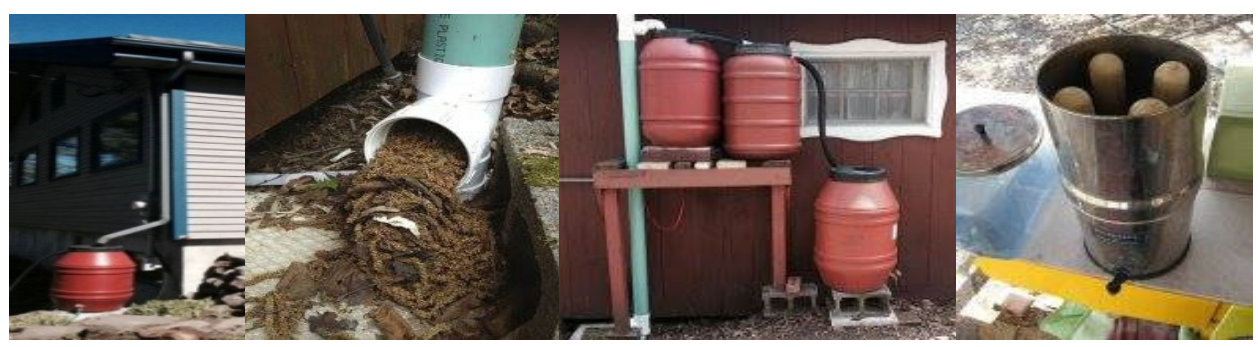

Figure 4: Rain barrels.

\section{ENVIRONMENTAL IMPACT ANALYSIS OF GI IMPLEMENTATIONS}

This section describes and examines the invaluable environmental impacts that can be achieved by using GI as follows:

- Reduces rainwater runoff flow

- Increases the city's water stock

- Reduces energy consumption

- Improves air quality

- Improves community liveability

\subsection{Environmental impacts of street harvesting}

Street harvesting reduces rainwater runoff, minimizing the negative impacts and problems caused by rainfall, especially in developing countries with poor infrastructure. On the other hand, this harvested water may be used in irrigation after being treated and filtered. It could reduce the amount of potable water being used residentially and increase the water supply, which is now a very important issue especially in Egypt.

Water use requires energy to produce and transport it, so street water harvesting may limit the energy required in only potable water and reduce the energy use in irrigation, landscaping and for washing purposes. When it saves energy, it may improve air quality and reduce atmospheric $\mathrm{CO}_{2}$.

\subsection{Environmental impacts of cultivated surface harvesting}

"Green roofs can store significant amounts of water in their growing media. This water is eventually evaporated from the soil or transpired by the plants on the roof, thus reducing the runoff entering sewer systems and waterways" [5].

A green roof gives additional insulation and reduces the amount of solar radiation reaching the building's roof, which can reduce a building's energy use.

In general, plants and cultivated surfaces absorbs atmospheric $\mathrm{CO}_{2}$, filter it and improve air quality. Trees in gardens and public green spaces provide shade; reduce wind speeds and provide a sense of place and well-being that may positively affect community liveability.

Fig. 5 matrix displays the relationship between implementation and environmental impacts which it will affect, not affect or maybe affect. 


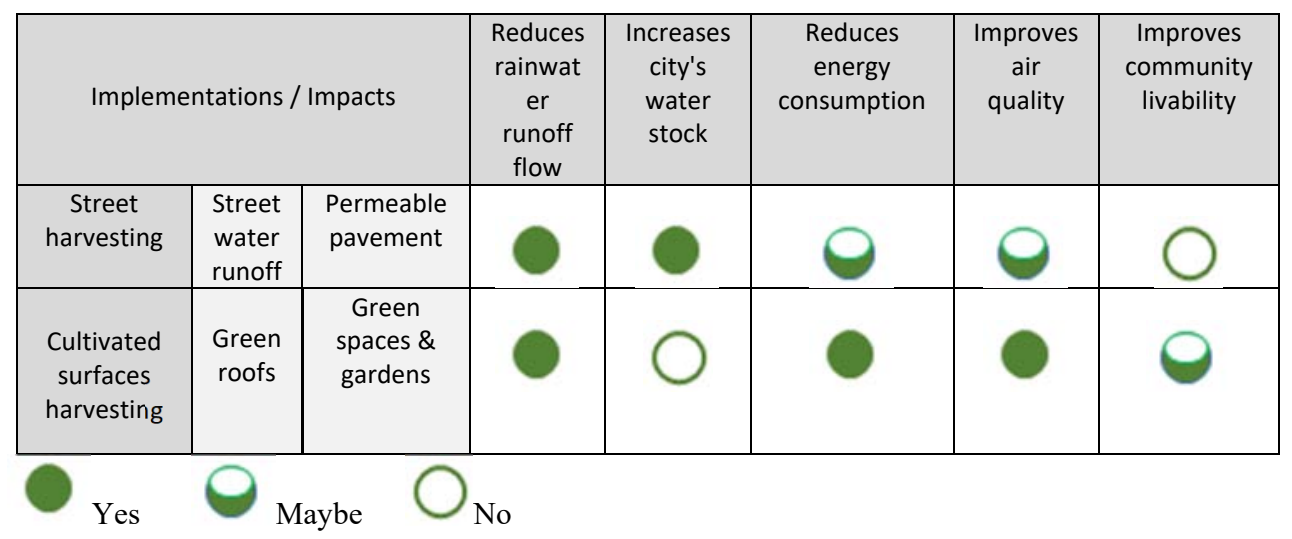

Figure 5: Implementation and impact matrix.

\section{FUTURE GI VISION FOR SMOUHA NEIGHBOURHOOD}

The Smouha neighbourhood is about 400000-square meters, located in the centre of Alexandria, overlooking the Sidi Gaber railway station and nearby El-Nozha international airport. It consists of residential areas and several other land uses.

The data was gathered by using a questionnaire form to survey the Smouha neighbourhood. Our results indicate that $74 \%$ of the residents suffer from many infrastructure-related problems, as follows:

- Frequent pressures due to its high density, like most of the residential neighbourhoods in Alexandria.

- Weakness in the sewer network, due to pressure on water and electricity networks resulting from continuous erection of new buildings: the built-up area equals $75 \%$ of the entire site.

- There is no integrated plan for rainwater recycling or harvesting of the rainfall in the neighbourhood streets, as shown in Fig. 6.

- The pavement, trees, green spaces aren't designed to capture rainfall onsite, and green roofs are currently being ignored.
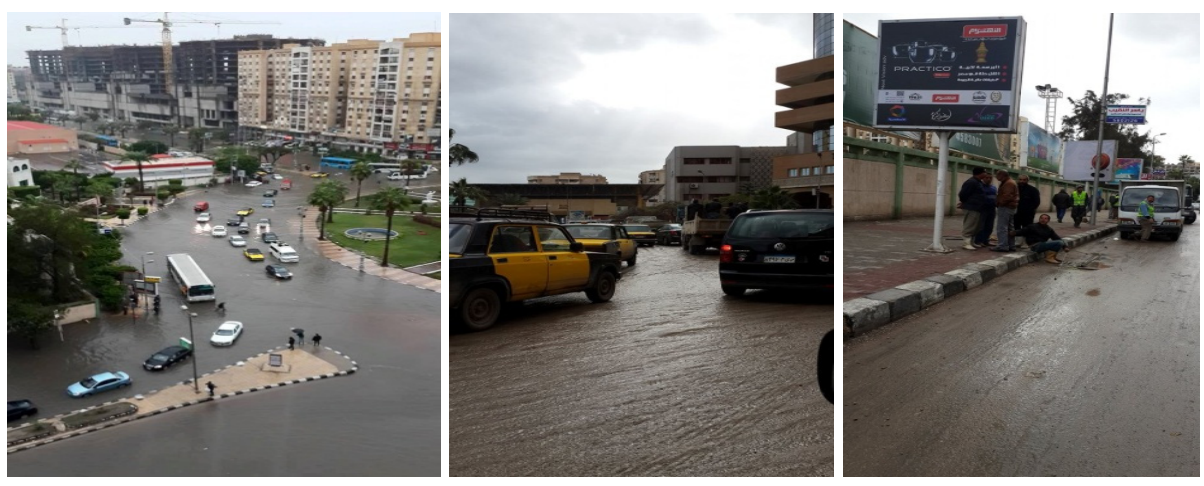

Figure 6: Rainfall situation in Smouha. 


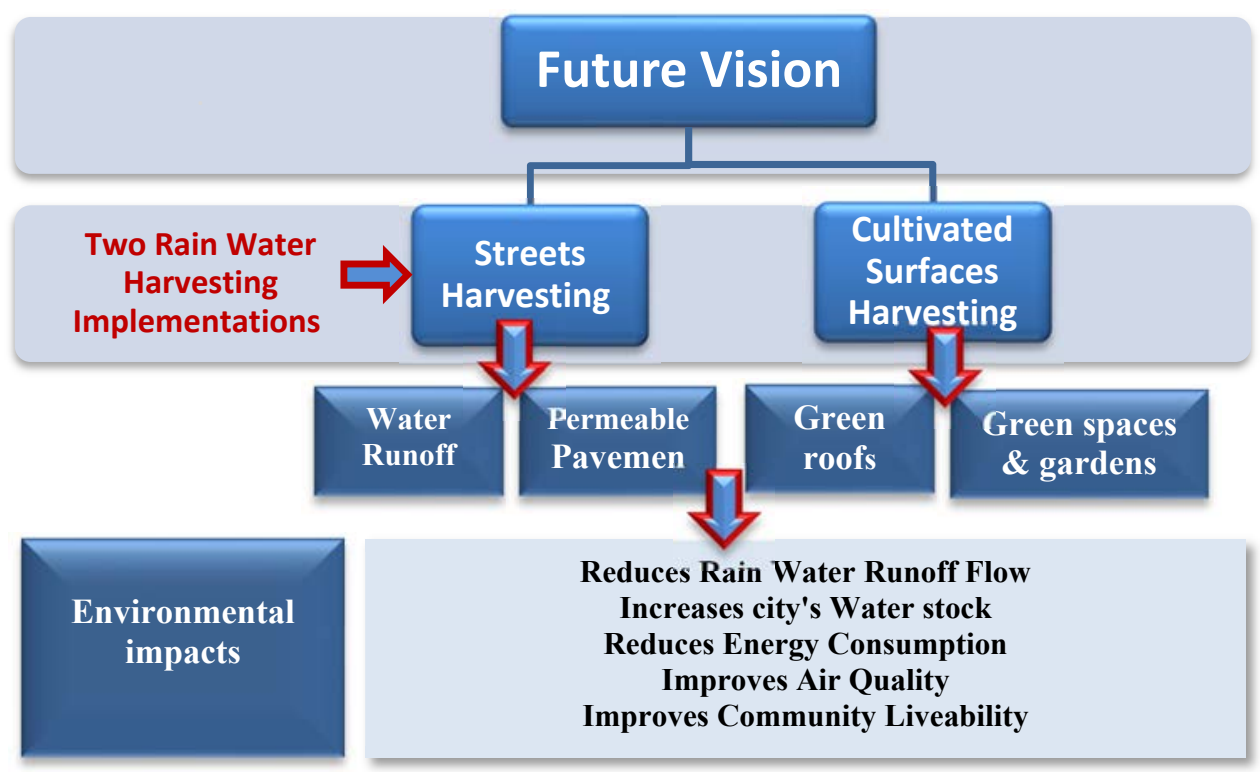

Figure 7: Future vision of rainwater management in Smouha.

In the following section, some proposals are described for a future vision of GI rainwater use, to overcome problems, as shown in Fig. 7.

\subsection{Street water harvesting in the Smouha neighbourhood}

\subsubsection{Water runoff}

Direct and capture street rainwater through pipes in storage tanks above or below ground, to reuse it in irrigation of planted areas in Smouha's squares or charged into soil to increase water recharge. Use rainwater sewer and storage systems (mentioned in 3.1.1) on the main streets (Victor Emanuel, Fouzy Moaaz, and 14 May streets).

\subsubsection{Permeable pavement}

Replace to make permeable pavements, instead of traditional ones. Use permeable pavers in paths and building courts, and permeable asphalt on the main streets.

\subsection{Cultivated services in the Smouha neighbourhood}

\subsubsection{Green roofs}

Installing a green roofing system on the existing buildings will increase the extra weight of the roofing system. In addition, it would give a higher cost to the existing structure. Therefore, the installation of green roofs on new buildings must be taken into consideration, while encouraging residents of old buildings to cultivate small plants in terraces or on the roofs of the existing buildings, due to the absence of green roofs.

Use the rainwater inlet for roof harvesting in new buildings constructions, where rainwater collects on roofs and terraces, and then makes its way down a pipe to a suction tank. A filter 
is placed in this tank to clear impurities in the water. A fitted sensor in the collection tank sends the water to the tank located on the terrace; where water is then supplied to the flats through the water storage tank, for domestic purpose usage.

\subsubsection{Green spaces and paths}

Green spaces and paths enhance all roads that penetrate the residential zone when the green paths are connected to each other, as shown in Fig. 8. Promote the cultivation of various types of trees for several benefits, within those green spaces and paths. Create walking paths to allow pedestrian access through the existing super block development.

Due to the energy crisis and environmental health disasters, initiating alternative means of transportation to the automobile is becoming increasingly emphasized in many cities, and is likely to increase in the future (Fig. 9). Green path creation refers to a wide range and means of transportation that reduces negative impacts. This could be achieved by:

1. Developing neighbourhoods that promote walking, as shown in Fig. 10.

2. Creating direct routes to shorten walking distances.

3. Designing paths that emphasize bike safety and convenience.

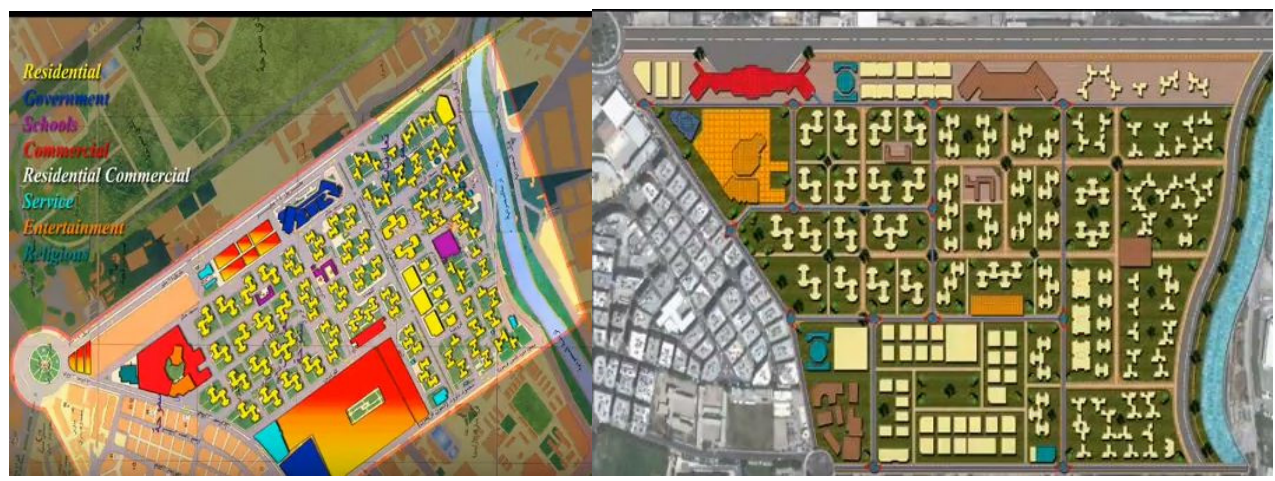

Figure 8: Site plan, before and after.

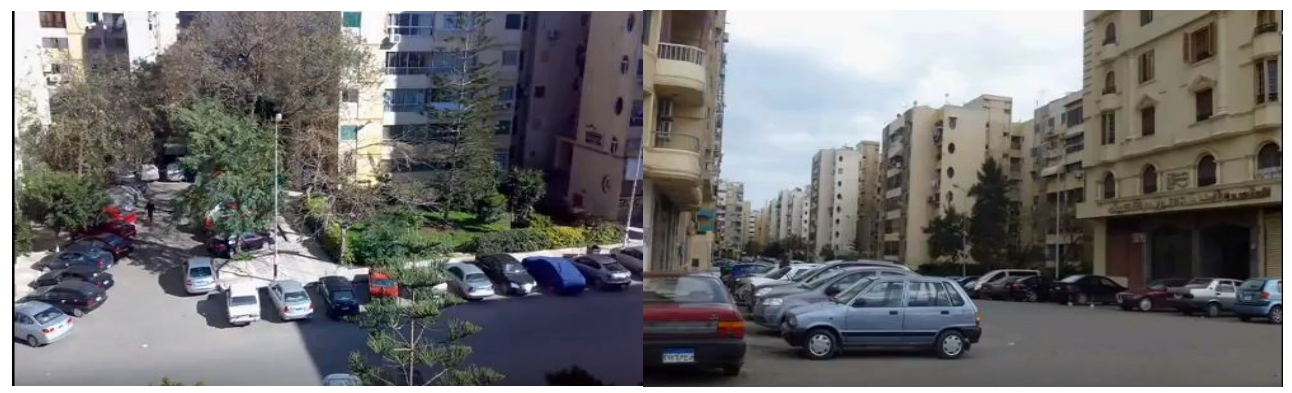

Figure 9: Car circulation penetrating the residential zone (before). 


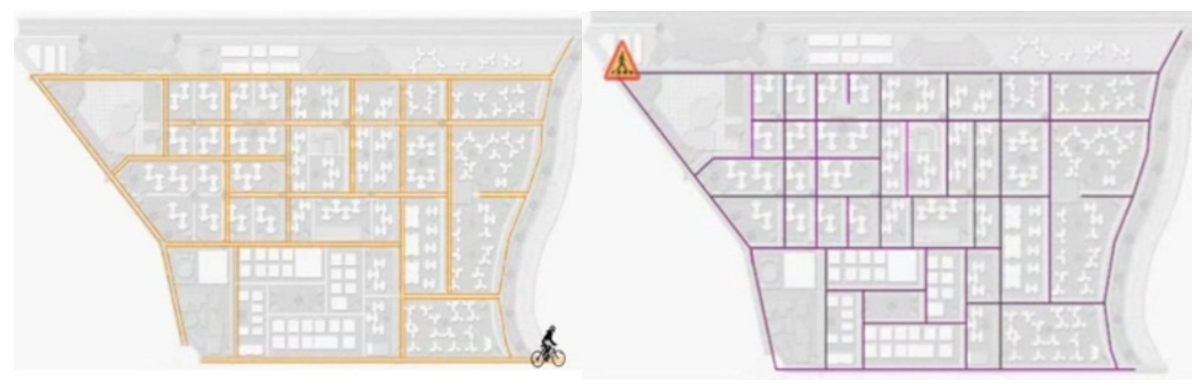

Figure 10: Pedestrian paths and ways for biking (after).

\section{CONCLUSIONS}

Flooding, drought and lack of water stocking are the most common world water problems which should fade by using a rainwater management plan. Rainwater management for GI develops and enhances community liveability in a city. It has a lot of advantages for social development because it increases green spaces, recreational areas and vegetation, in addition to providing improved economic and environmental impacts. On the economic side, rainwater management saves money, solves rainfall problems and can be considered a free source of water for irrigation and other purposes. The environmental impacts mentioned in this research will affect public health and will promote wellbeing while moving towards a sustainable community.

The following recommendations have significant implications for the future of cities using green infrastructure:

1. Countries going through rapid urbanization should comprehend the sustainable solutions to address its infrastructure.

2. An effective rainwater management plan should be provided, one which is cost effective, in order to achieve economic growth.

3. There should be integration of a Green Infrastructure into existing and new urban communities: Rainwater harvesting systems can improve or maintain watershed hydrology, reduce pollutant loading into receiving waters, increase water conservation, reduce stress on the existing infrastructure, and reduce energy consumption.

4. Decision-makers and stakeholders must encourage planners and designers of the vital role for applying Green Infrastructure guidance in the design of streets, landscapes, open spaces and in using green roofs in new building construction.

5. Providing municipalities with Green Infrastructure guiding principles, to be mentioned in the development of their integrated plans, would assist with the gain of significant economic development benefits.

\section{REFERENCES}

[1] Armour, T., Luebkeman, C. \& Hargrave, J., Cities Alive Rethinking Green Infrastructure, London, 2014.

[2] United Nations (UN) Environment Programme Division of Technology. Industry and Economics, Examples of Rainwater Harvesting and Utilisation around the World, www.unep.or.jp/ietc/publications/urban/urbanenv-2/9.asp. 
[3] Loos, F. \& Vliet, M., Green Streetscape Design with Storm-water Management. The Images Publishing Group: Australia, 2016.

[4] Canada Council for Green Building. Introduction to Rainwater Harvesting. www.ecohome.net/guide/introduction-rainwater-harvesting.

[5] Centre of Neighbourhood Technology, The Value of Green Infrastructure Guide to Recognizing Its Economic, Environmental and Social Benefits, 2010. 